Козлов Олег Игоревич, канд. техн. наук, консультант отдела развития мясомолочной промышленности и кооперации, Министерство сельского хозяйства Саратовской области. Россия.

410008 2. Саратов, 4-й Комсомольский $n p-\partial$, d. $2 / 6, \kappa в .24$.

Тел.: 89047007155; e-mail: Kozl0w@yandex.ru

Глебов Иван Петрович, $\partial-p$ экон. наук, проф. кафедры «Менеджмент и ВЭД в АПК», Саратовский го- сударственный аграрный университет имени Н.И. Вавилова. Россия.

410012, г. Саратов, Театральная пл., 1.

Тел.: (8452) 23-72-60; e-mail: glebovip@sgau.ru.

Ключевые слова: сельскохозяйственные потребительские кооперативы; государственная поддержка; развитие материально-технической базы.

\title{
SYSTEM OF MEASURES OF STATE SUPPORT OF AGRICULTURAL CONSUMER COOPERATION IN THE SARATOV REGION
}

Kozlov Oleg Igorevich, Candidate of Technical Sciences, consultant of the department of the meat and dairy industry and cooperation development, Ministry of Agriculture of the Saratov Region. Russia.

Glebov Ivan Petrovich, Doctor of Economic Sciences, Professor of the chair "Marketing and External Economic Activity", Saratov State Agrarian University named after N.I. Vavilov. Russia.

Keywords: agricultural consumer cooperatives; governmental support; development of material and technical base.
The measures of state support that agricultural consumers' cooperatives can get in the Saratov region are systematized. They can be divided into two groups for both small and medium-sized enterprises and agricultural producers. The analysis of existing measures of state support was carried out and the most effective ones in the economic and social aspects were identified using the example of agricultural consumer cooperatives of the Saratov region. Unresolved problems in the provision of state support measures have been identified and proposals for their solution have been made.

\section{МИГРАЦИОННЫЕ ПРОЦЕССЫ НА РОССИЙСКОМ РЫНКЕ ТРУДА}

\author{
кОНОВАЛОВА Татьяна Леонидовна, Саратовский национальный исследовательский \\ государственный университет имени Н.Г. Чернышевского
}

Рассмотрено состояние российского рынка труда, значительное место в котором отводится работникам, привлекаемым из-за рубежа. Выделены проблемы функционирования современного рынка труда и проблемы, возникающие в связи с привлечением иностранной рабочей силы как квалифицированных, так и неквалифицированных работников. Особое внимание уделено проблеме эффективного использования труда мигрантов в сельском хозяйстве.

Введение. В условиях глобализации, роста открытости границ экономик мира возрастает международная конкуренция. Наращивание конкурентных преимуществ становится одной из задач развития государств, возрастает роль конкурентоспособности экономики страны [11]. Одним из направлений повышения конкурентоспособности является привлечение в страну зарубежных трудовых ресурсов.

Модернизация российской экономики, переход ее на инновационный путь развития, формирование благоприятного инвестиционного климата Российской Федерации предполагают дальнейшее развитие стимулирующих механизмов регулирования трудовой миграции.

Методика исследований. Для российского рынка труда чрезвычайно актуальной является проблема международной трудовой миграции. Особое внимание исследователей привлекают аспекты, связанные с иммиграционными процессами. Анализируется их роль и влияние на рынок труда в России.

Теоретической и методологической основой написания данной статьи послужили труды российских экономистов $[3,5,6,7,8,10,12]$ и данные современной статистики. Затронуты как теоретические, так и в основном практические аспекты функционирования современного россий- ского рынка труда. В исследовании применялись общеметодологические принципы и приемы исследования, межстрановые сопоставления.

Результатьі исследований. Иммиграция сегодня - это целый комплекс реальных экономических и социальных проблем, накопившихся в течение десятилетий и затрагивающих интересы различных групп населения (см. таблицу). Нахождение решений этих проблем оказывается весьма непростой задачей.

Предпосылками столь широкого применения труда иностранных граждан стали не только демографические тенденции в стране, но и системные проблемы российского рынка труда. Одной из

Доля предприятий, привлекавших в 2009 г. иностранных работников, по основным отраслям экономики, \% от общего числа респондентов [3]

\begin{tabular}{|l|c|c|c|c|}
\hline Отрасли экономики & $\begin{array}{c}\text { Малый } \\
\text { бизнес }\end{array}$ & $\begin{array}{c}\text { Средний } \\
\text { бизнес }\end{array}$ & $\begin{array}{c}\text { Крупный } \\
\text { бизнес }\end{array}$ & В среднем \\
\hline Строительство & 27,5 & 29,6 & 27,0 & 28,3 \\
\hline Транспорт и связь & 21,9 & 30,3 & - & 22,4 \\
\hline $\begin{array}{l}\text { Обрабатывающее } \\
\text { производство }\end{array}$ & 17,9 & 19,3 & 25,0 & 21,2 \\
\hline $\begin{array}{l}\text { Сельское хозяйство, } \\
\text { охота и лесное } \\
\text { хозяйство }\end{array}$ & 5,4 & 23,1 & 50,0 & 16,9 \\
\hline $\begin{array}{l}\text { Оптовая и розничная } \\
\text { торговля, ремонт }\end{array}$ & 7,3 & 16,0 & 18,2 & 11,6 \\
\hline
\end{tabular}


них, в частности, является профессионально-квалификационный дисбаланс спроса и предложения рабочей силы. Запланированный на ближайшую перспективу экономический рост невозможен без масштабного пополнения миграционных трудовых ресурсов, даже при реальном повышении производительности труда. В нашей стране сейчас находится от 3 до 5 млн трудовых мигрантов (рис. 1). При этом, согласно утвержденной правительством квоте, в 2012 г. должны были получить легальный статус лишь 1,7 млн человек. В среднем по России в 2012 г. доля только легальной иностранной рабочей силы в общей численности занятых составляла $2,4 \%$ [4]. С учетом нерегулируемой трудовой миграции доля иностранной рабочей силы может приближаться к 10 \% общей численности занятых в России, что примерно соответствует доле иностранных работников в таких странах Европы, как Германия и Австрия [3].

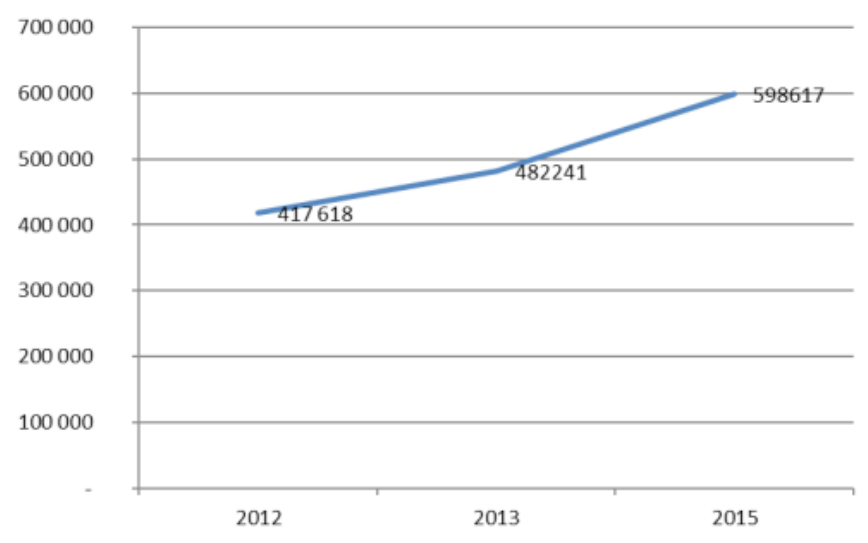

Рис. 1. Динамика роста численности международных мигрантов, прибывщих в РФ по годам [5]

Однакомигрантынеравномерно распределены по сферам экономики, в основном они концентрируются там, где не предполагается в ближайшее время внедрение эффективных трудосберегающих технологий: в торговле, общественном питании, строительстве, жилищно-коммунальном, сельском и лесном хозяйстве. На многих локальных рынках труда РФ уже сейчас существует абсолютный дефицит рабочей силы. В российском строительстве, например, доля иностранцев (без учета нелегальных работников) равняется $16 \%$, а с учетом нелегалов - в несколько раз больше [2].

Реформа российского миграционного законодательства в части привлечения иностранных работников, начавшаяся в 2006-2007 гг., проводится по нескольким направлениям. Одним из них является привлечение в Российскую Федерацию высококвалифицированных иностранных специалистов. С этой целью в 2010-2011 гг. был принят ряд законов о правовом положении иностранных граждан в Российской Федерации, направленных на создание комфортных условий для пребывания и осуществления трудовой деятельности высококвалифицированных специалистов в России. Другим направлением является легализация трудовых мигрантов, прибывающих в страну в безвизовом порядке и осуществляющих трудовую деятель- ность по найму у физических лиц. Здесь регулирование осуществляется путем внедрения патентов на осуществление такой деятельности. Ожидается дальнейшее увеличение количества привлекаемых высококвалифицированных иностранных работников в российскую экономику и увеличение количества иностранных граждан, осуществляющих трудовую деятельность в России по патентам.

По нашему мнению, следует ориентироваться на опыт развитых стран, достаточно широко привлекающих именно квалифицированных специалистов. Например, в Японии практически невозможно увидеть иностранца на стройке или на другой похожей работе, в то же время сотни иностранцев присутствуют «в дорогих бизнес-районах где-нибудь в банке или на каком-нибудь научном мероприятии» $[13,169]$. Иными словами, Японии нужны специалисты, ученые и мастера в определенной сфере деятельности, а не гастарбайтеры.

Востребованность высококвалифицированных иностранных специалистов во многих странах связана не с отказом местного населения от занятия определенных рабочих мест, а с нехваткой сотрудников, обладающих специальными знаниями, квалификацией для выполнения определенной работы. Такие специалисты занимают высокий сегмент рынка, оставляя средний для национальных работников. Низший сегмент рынка труда также пополняется малоквалифицированной и неквалифицированной рабочей силой из-за рубежа, занимающей рабочие места, непопулярные у национальных работников.

Мировой опыт показывает, что компании, практикующие найм сотрудников с различной культурной составляющей, зачастую оказываются более конкурентоспособными, чем традиционные монокультурные компании, использующие исключительно местную рабочую силу [8]. Причины этих преимуществ, как правило, связаны с более высокой гибкостью и открытостью к изменениям, внутренним культурным разнообразием, приводящим к более активному обмену опытом, знаниями и идеями.

Иностранная рабочая сила в настоящее время является неотъемлемой частью российского рынка труда, а ее привлечение и использование условием дальнейшего экономического развития (рис. 2). Эта ситуация обусловливает необходимость перестройки механизмов управления миграционными процессами.

Трудовая миграция тесно увязана с проблемами российского рынка труда в целом. Главная проблема - сильно заниженный уровень оплаты труда. Если исключить финансовый и нефтегазовый сектор, заработная плата в России занижена на всех уровнях квалификации. Более того, в ряде областей - соцзащита, сельское хозяйство, образование и ряде других - зарплата находится на уровне прожиточного минимума или даже ниже. «Если труд дешевый, то на рынке возникает негласная, теневая, не отражающаяся в статистике конкуренция за рабочие места. В реальности мы 


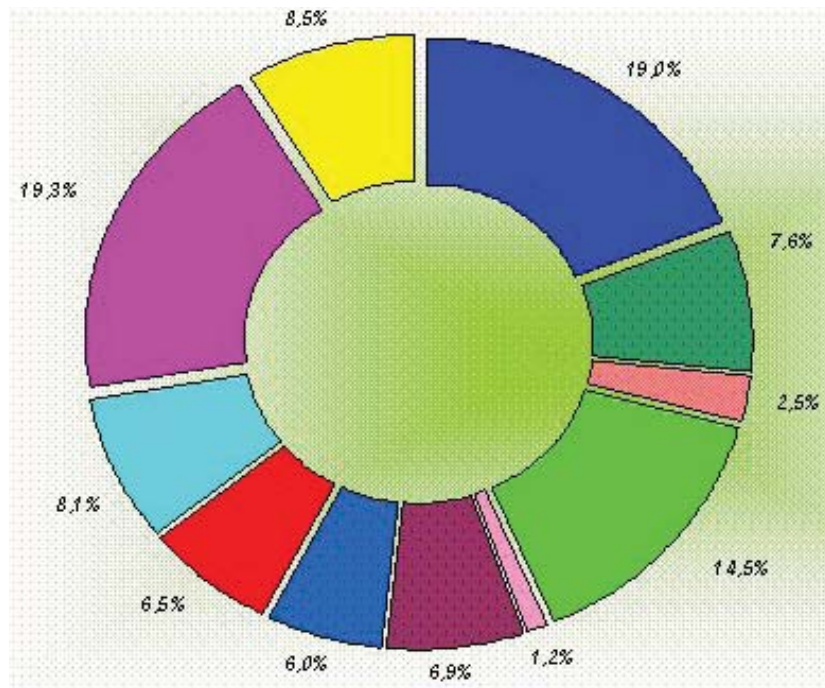

Рис. 2. Сферы деятельности, в которые привлекаются трудовые мигранты [12]

имеем дело с высоким уровнем дефицита «хороших» рабочих мест - с достойной заработной платой и адекватными условиями труда» [10].

Не менее важная проблема - массовое трудоустройство без оформления трудовых отношений. В особенности это касается молодежи с высшим образованием. Такие люди оказываются полностью зависимыми от работодателя. Не имея официально оформленных трудовых отношений, они автоматически лишаются трудовых прав.

Рост масштабов использования труда иностранных граждан в последние годы значительно осложняется ростом нелегальной трудовой иммиграции, которая может рассматриваться как еще одна серьезная проблема российского рынка труда. Проблема нелегальных мигрантов связана с их тяжёлым, зависимым положением на рынке труда. Обычно рассматривают связанные с мигрантами угрозы, но следует выделять и угрозы для мигрантов, исходящие от российского работодателя, связанные с их незащищенностью. Большинство мигрантов прекрасно понимают, что работать легально - значит иметь элементарные социальные гарантии, которых нелегальные работники полностью лишены. У бизнеса же противоположные интересы. Работодатель, преследуя собственную выгоду, делает выбор в пользу дешевой рабочей силы, зачастую провоцируя конфликт между местным населением и гастарбайтерами.

Многие временные трудовые мигранты, легализовавшись и обустроившись в России, стремятся остаться в стране на постоянное место жительства. Не получая поддержки (во многом из-за несовершенства законодательства) и не желая возвращаться на родину, они зачастую также пополняют ряды «нелегалов». Необходимо разрабатывать новые экономически стратегии, которые позволили бы не только взять под контроль рынок труда мигрантов, но и постепенно заменить неквалифицированный труд гастарбайтеров более технологичным и высокопроизводительным трудом местных работников. Требуется также повышение значимости труда и обеспечение защиты прав миг- рантов, что в современном мире является показателем цивилизованности государства.

Традиционно труд мигрантов широко применяется в различных отраслях сельского хозяйства. Правда, он носит все больше сезонный характер: в основном именно мигранты выступают в роли наемных рабочих в период уборки урожая. И речь идет не только о России - в ряде стран и регионов доля мигрантов, занятых в сельском хозяйстве, занимает до $80 \%$ от общего числа рабочих в этой отрасли. Именно такие результаты были получены Союзом товаропроизводителей и экспортеров в ходе проведенного им исследования рынка труда в отрасли сельского хозяйства. Если говорить о странах Европейского Союза, то ежегодно для проведения различных сельскохозяйственных работ в них привлекается около полумиллиона рабочих из стран, не состоящих в ЕС [1].

Так, в Испании около 80 \% всех работников сельскохозяйственной отрасли являются выходцами из стран Северной Африки, Центральной Америки и Восточной Европы. В Германии использование труда мигрантов доходит до 90 \%. В Малайзии на производстве риса занято более миллиона приезжих в основном из Индонезии. В США все производство зерновых держится исключительно на выходцах из Центральной и Латинской Америки.

Не секрет, что подавляющее большинство мигрантов, занятых в сельском хозяйстве, работают, а зачастую и находятся на территории вышеперечисленных стран нелегально. Проблема легализации трудовых мигрантов и создания для них равных конкурентных условий на внутреннем рынке - это задача любого правительства.

Немало гастарбайтеров занято и в сельском хозяйстве России и Казахстана. В России, несмотря на то, что в настоящее время сельскохозяйственная отрасль демонстрирует устойчивые темпы роста, стали активизироваться застаревшие изъяны и появляются новые риски и неопределенности в обеспечении отечественными компонентами всех импортных составляющих производства.

В период до 2026 г. ожидается замедление темпов роста как спроса, так и предложения на мировых продовольственных рынках, связанное с затуханием факторов роста прошлого десятилетия. Реальные цены на сельскохозяйственные товары обнаружат понижательный тренд, сохраняя при этом значительную волатильность. Сильное воздействие на перспективу процессов окажут сегодняшнее рекордное производство и высокие запасы большинства сельскохозяйственных товаров в мире. Специалисты отмечают, что прогноз неблагоприятен для России, которая перешла от политики импортозамещения к политике стимулирования 
экспорта продовольственной продукции. Наступающий период депрессивных цен означает, что российские экспортеры будут вынуждены «вытеснять» своих конкурентов - других игроков мирового рынка либо более высоким качеством, либо более низкими ценами, либо тем и другим [9]. И в этих условиях дешевый труд мигрантов может стать одним из решающих факторов, определяющих конкурентоспособность производимой продукции.

Миграционный поток сегодня складывается из сезонной миграции неквалифицированной и малоквалифицированной рабочей силы, индивидуальных предпринимателей, квалифицированных работников сферы услуг и «челноков». Так, например, в Казахстане «челноки» приезжают на оптовый рынок в г. Алматы на срок менее трех-пяти дней для закупки и перепродажи товара, увеличивая миграционную статистику.

Изучая опыт Казахстана в регулировании трудовой миграции, следует отметить, что на 1 января 2015 г. в Казахстане работали представители 144 стран, в том числе из Китая, Турции, Индии, Великобритании, Италии. На начало 2016 г. в Казахстане было задействовано 32,2 тысяч разрешений на привлечение иностранной рабочей силы [7]. Основная часть разрешений на привлечение иностранной рабочей силы пришлась на специалистов и квалифицированных рабочих. Рабочие, занятые на сезонных сельскохозяйственных работах, в основном прибывают из Киргизии и Таджикистана, располагающих сравнительно дешевой рабочей силой.

Сравнение миграционных проблем России и Казахстана возможно, т.к. это интегрирующиеся страны, имеющие во многом схожие экономические и миграционные проблемы. Исследователи отмечают, что, например, отличительной особенностью взаимной торговли России и Казахстана является то, что около 70 \% из объема общего товарооборота формируется за счет приграничной торговли и регионального сотрудничества. Российско-казахстанское приграничье включает в себя 12 российских и 7 казахстанских регионов, которые играют весомую роль для национальной экономики названных государств, участвуя в формировании основных показателей развития. В частности, валовой региональный продукт приграничных районов Казахстана составляет практически 43 \% ВВП страны [7].

Опрос респондентов показал, что есть несколько причин широкого привлечения труда мигрантов в республике Казахстан. На первом месте нежелание многих местных жителей работать в отрасли сельского хозяйства $-86 \%$. Вторая причина - желание самих мигрантов трудиться именно на этих работах как хорошо им знакомых и доступных, а также вынужденная сезонность такого трудоустройства, которая для большинства мигрантов является удобной 76 \%. Третьей причиной названа более высокая оплата труда, которую требуют местные жители за тот труд, который выполняют мигранты 67 \% [6].
Таким образом, сложившаяся ситуация удобна в первую очередь для работодателей, которым использование труда мигрантов дает очевидные бонусы в виде меньших затрат на заработную плату и большей зависимости мигрантов от них. Незнание законов, общая неграмотность и бесправность в среде приезжих позволяют работодателям ставить выгодные для них условия, нанимать и увольнять рабочих по своему усмотрению, без оглядки на социальные нормы и трудовой кодекс.

Заключение. Россия, став одним из центров притяжения обширных миграционных потоков, столкнулась со схожими выявленными в Казахстане проблемами. Опыт европейских стран также доказал, что приток трудовых мигрантов может стать катализатором неблагоприятных экономических процессов, главным из которых является сужение сферы применения национальных работников. Однако для России трудовая миграция в целом является позитивным явлением: несмотря на активный рост численности трудовых мигрантов, она не оказывает существенного негативного влияния на национальный рынок труда, а наоборот - является необходимой его составляющей, без которой данный рынок будет испытывать дефицит рабочей силы.

\section{СПИСОК ЛИТЕРАТУРЫ}

1. Антипова Ю.И., Соколова О.Ю. Экономическая оценка взаимодействия государств-членов Евразийского экономического союза // Аграрный научный журнал. - 2017. - № 3. - С. 76-81.

2. Вишневский А., Денисенко М., Мкртиян Н., Тюрюканова Е. Демографические изменения и экономика. Статья вторая // Демоскоп Weekly. - 2010. - № 431-432.

3. Гонтмахер Е. Мировые миграционные процессы: необходимость глобального регулирования // Вопросы экономики. - 2013. - № 10. - С. 136-146.

4. Данные Федеральной службы государственной статистики. - Режим доступа: www.gks.ru.

5. Дикусарова М.Ю., Кириллова А.А., Непокупная О.В. Влияние миграции на рынок труда Российской Федерации // Молодой ученый. - 2017. - № 2. - С. 399-402.

6. Использование труда мигрантов в сельском хозяйстве. - Режим доступа: https://inforr.ru/news/95.php.

7. Калиева С., Мельдаханова М. Особенности трудовой миграции в республике Казахстан // Общество и экономика. - 2017. - № 9. - С. 151 - 171.

8. Карачаровский В., Ястребов Г. Иностранные профессионалы в России // Общество и экономика. 2013. - № 11-12. - C. 169-165.

9. Комаров В. Мировое сельское хозяйство - 2026 // Экономист. - 2017. - № 12. - С. 82-87.

10. Комолов О. О безработице, миграции и российском рынке труда. - Режим доступа: http://comstol.info.

11. Соколова О.Ю., Колтырин Е.А., Сквориова В.А. Импортозамещение как стратегия промышленной политики // Известия высших учебных заведений. Поволжский регион. Общественные науки. - 2017. № 3. - С. 131-145.

12. Тихонов В. Социально-экономический аспект трудовой миграции в России // Студенческий научный форум 2011. Режим доступа: http://russian-scientists.ru/ communication/forum/forum76/topic1647/?PAGEN_1=2.

13. Шамов Д. Русский дух в стране самураев: жизнь в Японии от первого лица. - М., 2016. - 288 с. 
Коновалова Татьяна Леонидовна, старший преподаватель кафедры «Экономическая теория и национальная экономика», Саратовский национальный исследовательский государственный университет имени Н.Г.Чернышевского. Россия.
410013, г. Саратов, ул. Астраханская, 89.

Тел.: (8452) 21-36-41.

Ключевъе слова: рынок труда; международная трудовая миграция; труд мигрантов в сельском хозяйстве.

\title{
MIGRATION PROCESSES IN THE RUSSIAN LABOR MARKET
}

Konovalova Tatyana Leonidovna, Senior Teacher of the chair "Economic Theory and National Economics", Saratov National Research State University named after N.G. Chernyshevskiy. Russia.

Keywords: labor market; the international labor migration; work of migrants in agriculture.
The condition of the Russian labor market in which important place is allocated for the workers involved from abroad is considered. The problems of functioning of modern labor market and a problem arising in connection with involvement of foreign labor - both qualified specialists, and workers of low qualification are allocated. Special attention is paid to use of work of migrants in agriculture.

\section{МЕТОДОЛОГИЧЕСКИЕ ПОДХОДЫ К ИССЛЕДОВАНИЮ РЕСУРСНОГО ПОТЕНЦИАЛА СЕЛЬСКОХОЗЯЙСТВЕННЫХ ПРЕДПРИЯТИЙ}

\author{
МАКУХИНА Анастасия Васильевна, Саратовский государственный аграрный университет \\ имени Н.И. Вавилова
}

\begin{abstract}
Анализируются методологические подходы к исследованию ресурсного потенииала сельскохозяйственных предприятий. При этом обоснована необходимость первоочередного использования синергетического и системного подходов. Выявлена взаимосвязь между всеми методологическими подходами, применяемыми как на промышленных, так и на сельскохозяйственных предприятиях. Выявлены основные факторы, влияющие на эффективность управления их ресурсным потенциалом. Рассмотрен механизм управления ресурсным потенщиалом сельскохозяйственного предприятия в разрезе его системной сущности, раскрыто его понятие и значение.
\end{abstract}

Введение. Ресурсный потенциал предприятия, согласно общепринятому мнению, - это совокупность его возможностей по производству товаров и оказанию услуг, которая включает в себя внутренние переменные и управленческий потенциал. В рыночной экономике потенциал предприятия зависит от внутренних факторов и от спроса потребителя, экономической ситуации в стране, действий конкурентов и других факторов. Ресурсы представляют собой не что иное как материальную основу начала производства. В зависимости от характера производства и его технологических особенностей ресурсы могут позволить получение разных по объему, эффективности и качественных характеристик конечных результатов труда. Такой подход к категории «ресурсы», послужил основанием для ученых присоединить их к расходной части процесса производства, т.е. ресурсы характеризуют лишь то, что может быть использовано, а не то, что может быть получено в результате осуществления производственного процесса. Иными словами, ресурсы представляют собой диалектическую противоположность результатам производства. Они обусловливают результаты, находятся с ними в неразрывном единстве, но не тождественны им [18]. Целью данного исследования является выявление необходимых методологических подходов к анализу процесса управления ресурсным потенциалом сельскохозяйственных предприятий. При этом автор понимает под методологией совокупность приемов и методов исследования, применяемых в различных науках.

Актуальность исследования данной темы обусловлена изучением методологических подходов к исследованию ресурсного потенциала, применимых на сельскохозяйственных предприятиях, главная задача которых - обеспечение продовольственной безопасности страны в условиях политики импортозамещения [12]. Для рассмотрения показателей предприятия необходимо использовать некоторые методологические подходы к формированию механизма управления ресурсным потенциалом. В данной работе рассмотрены такие методологические подходы, как синергетический, системный, генетический и динамический, воспроизводственный, процессный, функциональный, комплексный и ситуационный.

Теоретическая и практическая ценность системного подхода к организации была продемонстрирована Б. Ливихудом и Ф. Глазлом в исследовании «Динамическое развитие предприятия» [3]. Согласно их мнению, предриятие - это результат сложного взаимодействия факторов внешнего и внутреннегомираи одновременнопродукт деятельности человека продукт деятельности человека. Современная теория функционирования организаций формировалось начиная с конца девятнад- 